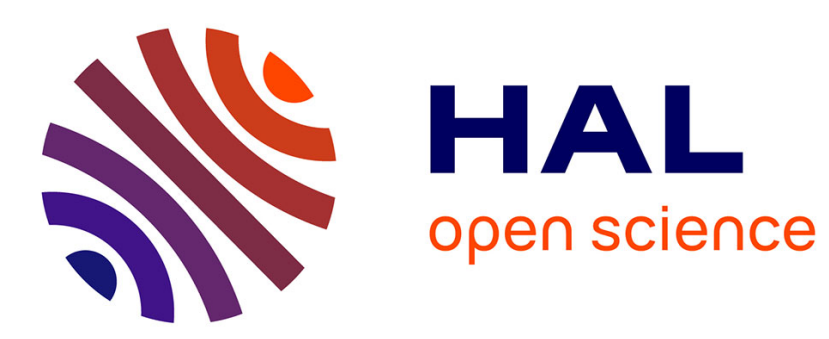

\title{
The Enigma of Methane on Mars
}

Franck Lefèvre

\section{To cite this version:}

Franck Lefèvre. The Enigma of Methane on Mars. Barbara CavalazziFrances Westall (eds). Biosignatures for Astrobiology, Springer, pp.253-266, 2018, 978-3-319-96174-3. 10.1007/978-3-319-961750_12 . insu-01886629

\section{HAL Id: insu-01886629 \\ https://hal-insu.archives-ouvertes.fr/insu-01886629}

Submitted on 2 Aug 2021

HAL is a multi-disciplinary open access archive for the deposit and dissemination of scientific research documents, whether they are published or not. The documents may come from teaching and research institutions in France or abroad, or from public or private research centers.
L'archive ouverte pluridisciplinaire HAL, est destinée au dépôt et à la diffusion de documents scientifiques de niveau recherche, publiés ou non, émanant des établissements d'enseignement et de recherche français ou étrangers, des laboratoires publics ou privés. 


\title{
Biosignatures for Astrobiology - Chapter 12
}

\section{The enigma of methane on Mars}

Franck Lefèvre ${ }^{1}$

\begin{abstract}
Between 2004 and 2012, four independent groups reported detections of low levels (10-60 ppbv) of methane on Mars. If true, these constitute the first observations of a potential biosignature on that planet and would be an important finding and addition to the inventory of minor species in its atmosphere. However, these claims for the presence of methane have been highly controversial. In 2014, the most robust search for methane on Mars was performed by the rover Curiosity. The latest measurements by Curiosity indicate a background $\mathrm{CH}_{4}$ level of 0.2-0.7 ppbv, except during a two-month period between November 2013 and January 2014, when high mixing ratios of around 7 ppbv were observed. These observations immediately raise the question of the origin of methane on Mars, but also pose fundamental challenges to our current understanding of Martian atmospheric physics and chemistry.
\end{abstract}

\subsection{Observations}

After many years of unsuccessful search, the first report of methane detection on Mars was made by Krasnopolsky et al (2004), who observed 10 $\pm 3 \mathrm{ppbv}$ of methane in January 1999 at $L_{\mathrm{s}}=88^{\circ}$ using the Fourier Transform Spectrometer (FTS) at the Canada-France Hawaii Telescope. This averaged value was obtained over a significant part of the Martian disk. The same year, Formisano et al (2004) detected varying amounts of methane between 0 and $30 \mathrm{ppbv}$ over a few orbits of the Planetary Fourier Spectrometer (PFS) infrared sounder on board the Mars Express space-

\footnotetext{
${ }^{1}$ Franck Lefèvre

LATMOS, CNRS/Sorbonne Université, Paris, France

E-mail: franck.lefevre@latmos.ipsl.fr
} 
craft. Geminale et al (2011) expanded on this using the same instrument and method over a six-year baseline. Their results revealed substantial seasonal variations of methane, with local enhancements of up to $70 \mathrm{ppbv}$ located at high northern latitudes in summer. The mean value derived from PFS is about 15 ppbv. Using the CSHELL spectrometer at the IRTF (Hawaii), Mumma et al (2009) detected, during in January-March 2003, a strong local enhancement ( $50 \mathrm{ppbv})$ in the form of a "plume" of methane at low latitudes over the Syrtis Major region (Fig. 12.1). No significant amounts of methane were found in their observations performed three years later in January-February 2006. Krasnopolsky (2012) reprocessed the CSHELL observations of February 2006 at $\mathrm{L}_{\mathrm{s}}=10^{\circ}$ with refined analytical approaches and found about $10 \mathrm{ppbv}$ of methane over the Valles Marineris region and $\sim 3 \mathrm{ppbv}$ outside this region. His observations for December 2009 at $\mathrm{L}_{\mathrm{s}}=20^{\circ}$ and March 2010 at $\mathrm{L}_{\mathrm{s}}=70^{\circ}$ showed no detection with an upper limit of 8 ppbv. Villanueva et al (2013) also used the CSHELL spectrometer in January 2006 but could only derive an upper limit of 7.8 ppbv, in contrast to the 10 ppbv detected by Krasnopolsky (2012) one month later. Villanueva et al (2013) did not detect methane in their later observations of November 2009 and April 2010.
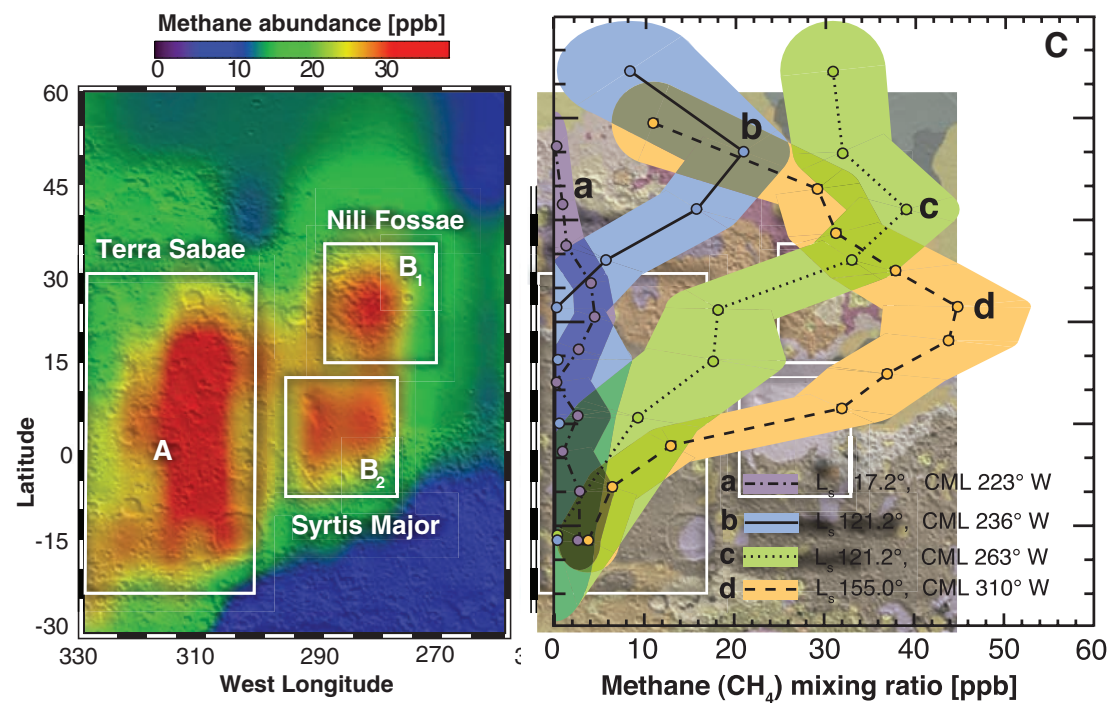

Figure 12.1. Methane mixing ratio (ppbv) observed from Earth by Mumma et al (2009). Left: regions where methane appeared enhanced during summer $2003\left(\mathrm{~L}_{s}=121^{\circ}-155^{\circ}\right)$. Right: latitudinal and temporal variability of methane. Profile ' $a$ ' was obtained in February 2006 at $\mathrm{L}_{\mathrm{s}}=17.2^{\circ}$. Profiles 'b', 'c', and 'd' were obtained in January-March 2003 between $\mathrm{L}_{\mathrm{s}}=121^{\circ}-155^{\circ}$. From Mumma et al (2009). 
All of the above studies measured $\mathrm{CH}_{4}$ in its absorption band at $3.3 \mu \mathrm{m}$. Using the band at $8 \mu \mathrm{m}$, Fonti and Marzo (2010) performed a statistical analysis of the Thermal Emission Spectrometer (TES) spectra acquired from the Mars Global Surveyor spacecraft and extracted a weak signal attributed to methane absorption. They found seasonally variable methane at the $\sim 10-30$ ppbv level.

It is important to recognise that the claimed detections at such low levels of methane were obtained at the limits of the instrumental capabilities. PFS and TES spacecraft instruments do not have the required sensitivity and spectral resolution for the unambiguous identification of $\mathrm{CH}_{4}$ (Zahnle et al 2011). Instead, the detection of methane is made by summing together thousands of spectra, which does not suppress - and can even increase instrumental effects and systematic errors. Despite their much greater spectral resolution, ground-based observations are not simpler because Martian methane must then be viewed through the atmosphere of Earth, which contains $\sim 10^{*}$ more methane molecules above the observer than that which is retrieved on Mars. The measurements must therefore exploit the Doppler shift of the Martian lines when Mars is approaching or receding from Earth. However, even in these conditions, the claimed detections of methane are close to the noise level. In any case, the very different geographical distributions and seasonal variations of methane obtained from the Earth (Mumma et al 2009; Krasnopolosky 2012) and from space (Fonti and Marzo 2010; Geminale et al 2011) are puzzling and must be considered with great care.

Because of the potential implications of the presence of methane, and in the light of the controversial observational dataset described above, the first in situ measurements promised by the Tunable Laser Spectrometer (TLS) aboard the Curiosity rover and its far superior detection capabilities were eagerly awaited. TLS uses an infrared laser at 3.27 microns to scan the same methane lines as PFS or from the Earth, but at ultra-high spectral resolution. TLS has two measurement modes: the direct ingest mode with error bars on the order of $2 \mathrm{ppbv}$ and the enriched mode achieved by scrubbing out $\mathrm{CO}_{2}$ during a slow fill of the sample cell. This latter mode has error bars of only about $0.1 \mathrm{ppbv}$. The first atmospheric samples collected by TLS in Gale Crater $\left(4^{\circ} \mathrm{S}, 137^{\circ} \mathrm{E}\right)$ spanned an eight-month period in spring-summer. By combining all of the individual measurements available at that time, it was concluded that methane was not detected, with an upper limit of only $1.3 \mathrm{ppbv}$ (Webster et al 2013). In a subsequent analysis, Webster et al (2015a) presented the entire TLS dataset reprocessed over a period of almost one Martian year (605 Martian days or sols). The results indicate detection of methane at two levels of abundance (Fig. 
12.2). A "background" $\mathrm{CH}_{4}$ level of $0.7 \pm 0.2 \mathrm{ppbv}$, based on high-precision methane-enriched experiments, is observed during the first 8 months and last 4 months of the dataset. Between these two periods, two episodic enhancements of methane were observed. The first was detected in June 2013 with a single measurement indicating about 6 ppbv of $\mathrm{CH}_{4}$ followed by a drop to 2 ppbv one week later. The second was observed in November 2013-January 2014 (sols 466-526 in Figure 12.2). During that period - corresponding to the Martian spring $\left(\mathrm{L}_{\mathrm{s}}=56-82^{\circ}\right)$ - four sequential measurements of TLS indicated a pulse of $7 \pm 2$ ppbv of methane over two months.

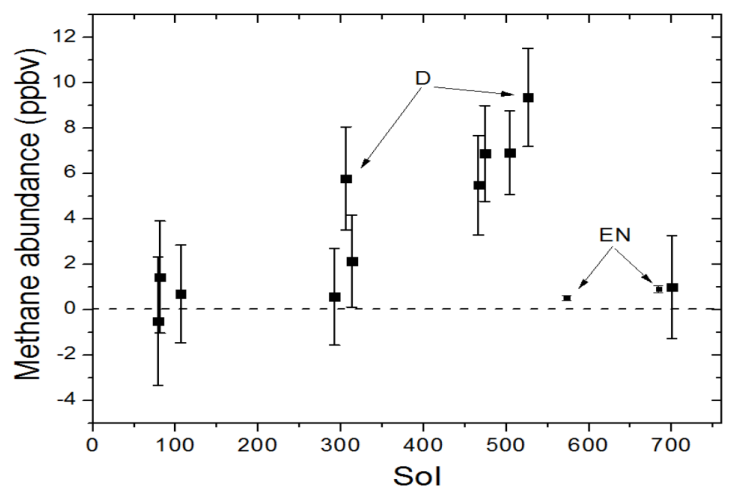

Figure 12.2. Measurements of methane mixing ratio (ppbv) by the TLS instrument on the Curiosity rover, as presented by Webster et al (2015a). 1 sol $=1$ Mars day $=24 \mathrm{hr} 37 \mathrm{mn}$. Martian sol 1 was on August 6", 2012. Error bars represent \pm 1 standard error of the mean. All measurements were made at night, except for the two marked " $D$ " ingested during the day. The values with smaller error bars labelled EN were retrieved from the "methane enrichment" runs. From Webster et al (2015a).

The duration of this event ( 60 sols) followed by a sudden drop to $0.5 \mathrm{ppbv}$ 47 sols later was interpreted by Webster et al (2015a) to result from a local production of methane that, once terminated, dispersed quickly. One Martian year later (in Martian year 33, according to the calendar proposed by Clancy et al (2000) which starts at $\mathrm{L}_{\mathrm{s}}=0^{\circ}$ on 11 April 1955), no springtime pulse of methane was observed by TLS (Fig. 12.3). On the contrary, the instrument only detected a very small background level of 0.2 ppbv by means of a high-precision enriched run (Webster et al 2015b). This absence of reproducibility from one year to the next seems to rule out a seasonal effect. Thus, if the TLS findings are true, the in situ evidence for the presence of methane on Mars can be summarised as follows. 1) Methane is constantly present at very low levels $(0.2-0.7 \mathrm{ppbv})$ in the Martian atmosphere. This equilibrium level requires a tiny source of less than 20 tonnes per year in order to balance the photochemical loss of methane over its at- 
mospheric lifetime of 300 years (Lefèvre and Forget 2009). 2) TLS observed two pulses of methane ten times higher than the background methane level during its first Martian year on the surface. Such events were not observed in the second year. This suggests the presence of local and episodic releases of methane, which are not correlated to season. The occurrence of methane pulses at the surface has not yet been confirmed by TLS high-precision "enriched" runs.

TLS methane mixing ratio

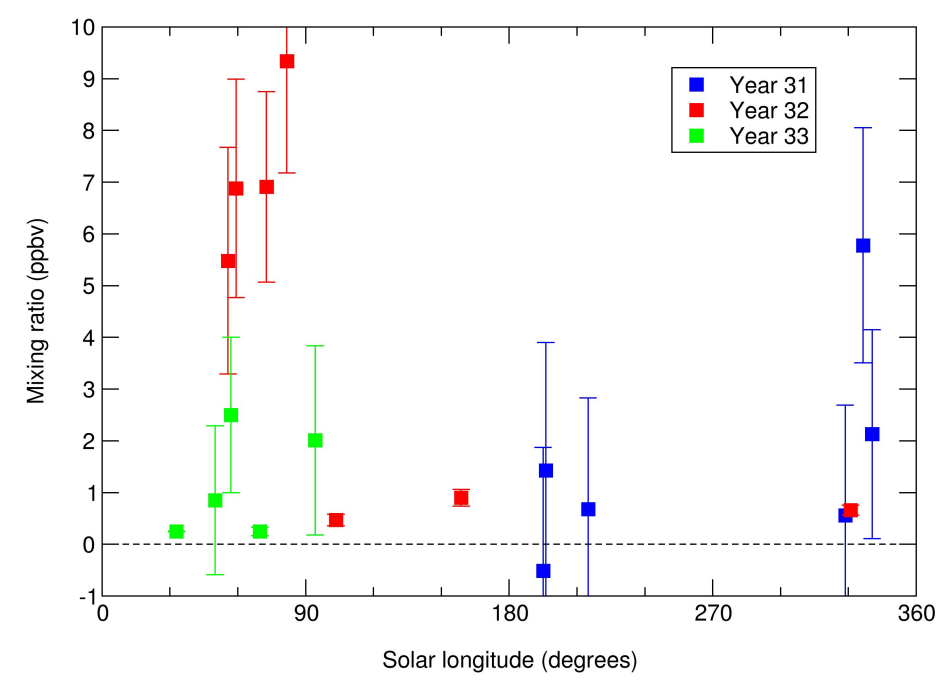

Figure 12.3. Summary of TLS methane measurements vs. solar longitude for the Martian years 31 to 33 (October 2012-January 2016). Error bars represent \pm 1 standard error of the mean. From data published by Webster et al (2015a) and Roos-Serote et al (2016)

\subsection{Methane production}

The observational claims for methane on Mars naturally raise the question of sources and sinks. On Mars, methane is not produced photochemically in the atmosphere and is destroyed by ultraviolet radiation and oxidants in approximately 300 years. Therefore, the presence of methane in the atmosphere, even in very small quantities, requires on-going (or very recent) emission from the surface. On Earth, more than $90 \%$ of methane has a biological origin, in the form of living beings, organic waste or fossilized matter. It is therefore tantalising to relate the existence of methane on Mars to a possible past or extant life on the planet. For instance, Krasnopolsky 
(2006) calculated that methane originating only from the impacts of comets, meteorites, and interplanetary dust is insignificant, and further argued that the lack of volcanism, hot spots, and $\mathrm{SO}_{2}$ (which is more abundant than $\mathrm{CH}_{4}$ in terrestrial outgassing) favours the hypothesis of a biogenic origin for Martian methane. However, if a microbial source is a possibility to explain the existence of methane on Mars, it is by no means the only one. To be convinced of this, one merely has to consider the estimated mass of methane transferred to the Mars atmosphere each year - a few tens of tons are sufficient to explain the background level measured by TLS to the abiotic $\mathrm{CH}_{4}$ flux on Earth, which is estimated at several megatons per year (Etiope and Sherwood Lollar 2013). On Earth, methane can indeed be produced in several specific environments by chemical reactions that do not involve organic matter. These processes are found at high temperatures in volcanic or geothermal areas, and at low temperatures in aquifers via gas-water-rock interactions. In this latter case, Atreya et al (2007) proposed that methane could be produced abiogenically by hydrothermal processes, such as serpentinization, i.e., the reaction between ultramafic $(\mathrm{Mg}, \mathrm{Fe}-\mathrm{rich})$ silicates and water, producing serpentine and molecular hydrogen $\mathrm{H}_{2}$ :

$$
(\mathrm{Mg}, \mathrm{Fe})_{2} \mathrm{SiO}_{4}+\mathrm{H}_{2} \mathrm{O} \rightarrow \mathrm{Mg}_{3} \mathrm{Si}_{2} \mathrm{O}_{5}(\mathrm{OH})_{4}+\mathrm{Mg}(\mathrm{OH})_{2}+\mathrm{Fe}_{3} \mathrm{O}_{4}+\mathrm{H}_{2}
$$

The aqueous $\mathrm{H}_{2}$ produced above then reacts with $\mathrm{CO}_{2}$ via a FischerTropsch-type reaction which in turn produces methane, e.g.:

$$
\mathrm{CO}_{2}+4 \mathrm{H}_{2} \rightarrow \mathrm{CH}_{4}+2 \mathrm{H}_{2} \mathrm{O}
$$

At the Mid-Atlantic Ridge, a substantial production of methane by serpentinization has been detected at relatively mild temperatures $\left(<100{ }^{\circ} \mathrm{C}\right.$, Kelley et al 2005), which could also be found on Mars at depths of 2-3 km below the surface (Oze and Sharma 2005). Although the presence of such aquifers is yet to be discovered on Mars, the discovery of methane in the atmosphere increases the possibility of active hydrothermal activity and a geologically "living" planet.

Exogenous methane sources, such as comets, meteorites, or interplanetary dust particles, are also a possibility. Court and Sephton (2009) studied direct release of $\mathrm{CH}_{4}$ by ablation and pyrolysis of carbonaceous meteorites during their atmospheric entry. They found that this process accounted for less than $10 \mathrm{~kg}$ of methane annually, which is a negligible fraction of the mass required to maintain the abundance of methane observed by TLS. On the other hand, Keppler et al (2012) argued that Murchison-type carbonaceous micrometeorites might be in sufficient quantity on the surface of 
Mars to become a significant abiogenic source of methane when exposed to ultraviolet radiation. The extrapolation of their laboratory experiment to the global scale suggests that 10-800 tons of methane could be produced annually at the surface of Mars, which could explain a substantial fraction - if not all - of the observed abundance of methane.

However, it is important to note that none of the processes mentioned above can explain the temporal variability of Martian methane that seems to emerge from the observations. Since it has been shown that high methane episodes do not correlate with predicted meteor events (Roos-Serote et al 2016), we may discard the hypothesis of meteor showers as a source of methane variability on Mars.

\subsection{Methane loss}

According to conventional chemistry, which reproduces very well the observed methane distribution and variations on Earth, the photochemical loss of methane on Mars is accomplished either by photodissociation or by chemical reactions. The fields of action of both processes are clearly separated in altitude. In the upper atmosphere, methane is photolyzed in the Lyman- $\alpha$ line at $121.6 \mathrm{~nm}$. The efficiency of this process peaks at about 80 $\mathrm{km}$ and represents $50-60 \%$ of the total loss of methane integrated over the atmospheric column. In the lower atmosphere, as on Earth, the loss of Martian methane occurs through hydrogen abstraction reactions with $\mathrm{OH}$ and $O(D)$, which initiate the methane oxidation chain. On Mars, the importance of oxidation by $\mathrm{OH}$ over that by $\mathrm{O}(\mathrm{D})$ depends strongly on the season but, overall, the sum of both reactions represents the remaining 40$50 \%$ of the total loss of methane.

These processes lead to a global chemical lifetime of methane on Mars estimated by state-of-the-art models of 300-340 terrestrial years (Summers et al 2002; Krasnopolsky 2004; Lefèvre and Forget 2009). From this lifetime can be calculated the rate of globally supplied methane required to maintain a steady-state mixing ratio in the atmosphere: as mentioned above, less than 20 tons per year of methane transferred to the atmosphere are sufficient to maintain the steady-state value of about $0.5 \mathrm{ppbv}$ measured by TLS. This mass may be compared with a terrestrial value on the order of $600 \times 10^{\circ}$ tons per year (Ciais et al 2013). Can such a faint source create the variability of methane observed on Mars? Lefèvre and Forget (2009) investigated this possibility by implementing highly localized and sporadic sources with the LMD global climate model (GCM). As expected from the 300-year lifetime of methane on Mars, their results showed that methane should be homogeneously mixed by atmospheric transport across most of 
the planet. A striking feature of GCM simulations of methane, however, is the large enrichment in methane that results from the condensation of $\mathrm{CO}_{2}$ gas at high latitudes in winter (Fig. 12.4). This is a well-established process, identical for all non-condensable species, as proven by observations of argon (e.g., Sprague et al 2007) and carbon monoxide (Encrenaz et al 2006).

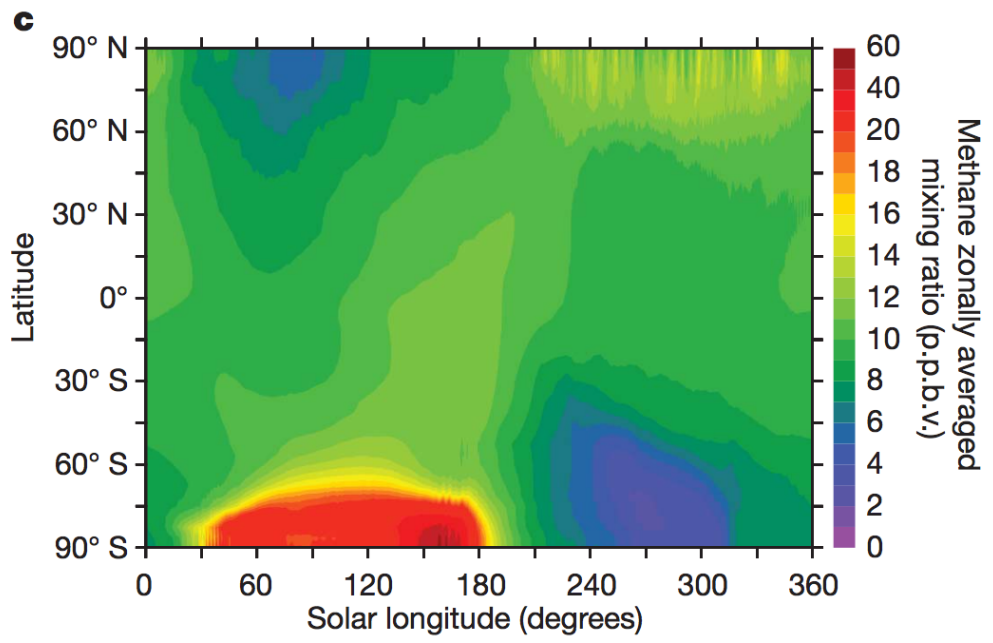

Figure 12.4. Seasonal evolution of the zonally averaged methane mixing ratio calculated by a global climate-chemical model. The simulations include a local source at the surface near the Equator. The amount of methane released from the source balances the global photochemical loss integrated over the Martian year, assuming an equilibrium value of 10 ppbv. The lifetime of methane is 330 years as determined by conventional chemistry. From Lefèvre and Forget (2009).

Conversely, $\mathrm{CH}_{4}$ is depleted at high-latitudes when $\mathrm{CO}_{2}$ sublimates from the polar cap in summer and returns to the gas phase. At low latitudes, the slow seasonal modulation of methane driven by the condensationsublimation cycle of $\mathrm{CO}_{2}$ is greatly attenuated. This effect calculated by the LMD GCM at Gale Crater is shown in Figure 12.5. It induces a peak-topeak change in $\mathrm{CH}_{4}$ of about $25 \%$ and a maximum mixing ratio obtained shortly before equinox $\left(\mathrm{L}_{s}=160^{\circ}\right)$. This theoretical result is here compared only to the high-precision measurements of TLS that are representative of a low background level of $\mathrm{CH}_{4}$, which in principle should vary like those of any other non-condensable species. Figure 12.5 shows that the maximum value of background methane measured by TLS ( $0.9 \mathrm{ppbv})$ is also obtained near $\mathrm{L}_{\mathrm{s}}=160^{\circ}$. However, the change in background methane ob- 
served in the first half of the Martian year appears to be much stronger (by one order of magnitude) than what is expected from the GCM and from only the condensation-sublimation cycle of $\mathrm{CO}_{2}$. This puzzling fact will have to be confirmed by new observations covering a greater part of the Martian year.

$$
\mathrm{CH}_{4} \text { at Gale crater }
$$

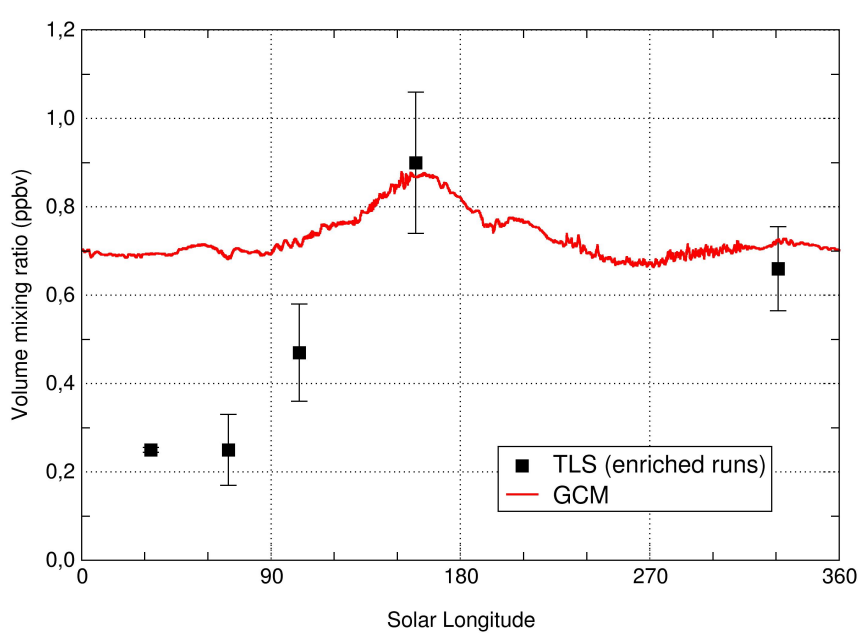

Figure 12.5. Seasonal evolution of the background methane levels measured at Gale Crater by the TLS instrument aboard the Curiosity rover (only high-precision "methane enriched" runs are included) and simulated by the LMD global climate model (GCM) assuming conventional methane chemistry. The slow variation of methane visible in the model simulation is only due to the condensation-sublimation cycle of $\mathrm{CO}_{2}$ at the Martian poles. TLS data are from Webster et al (2015a) and Roos-Serote et al (2016).

Using GCM simulations, Lefèvre and Forget (2009) showed that reproducing the Earth-based observations of methane by Mumma et al (2009) required a methane lifetime shorter than $\sim 200$ days, and hence an unknown sink that is at least 600 times faster than the loss derived from the current kinetics data used by the atmospheric chemistry community. In what follows, we present GCM simulations of methane carried out in an attempt to reproduce the full set of TLS measurements, including the spike of $7 \mathrm{ppbv}$ observed in the spring of Mars Year 32. For each model experiment, methane is continuously released from a single location chosen among nine sites located in the hemisphere centred on Gale Crater (Fig. 12.6, left). The production of methane is assumed to be continuous, since both serpentinisation (occurring a few kilometers below the surface) and the action of ul- 
traviolet radiation on organics (widespread on the surface) are unlikely to be episodic over short timescales. In a first step, the lifetime of methane is arbitrarily assumed to be 1 terrestrial year. This is similar to the suggestion by Lefèvre and Forget (2009) to match the measurements of Mumma et al (2009). In the case of the TLS measurements, a lifetime of 1 year implies an emission of 6000 tons $\mathrm{yr}^{-1}$ in order to maintain the background level of 0.7 ppbv suggested by the instrument. Such a source would be 40 times more significant than the largest abiotic gas seep known to date on Earth (Chimaera in Turkey, Etiope and Sherwood Lollar 2013). This hypothesis is unlikely but required in order to approach the TLS measurements with model simulations. Figure 12.6 (right) shows the methane mixing ratio obtained at Gale Crater when methane is continuously released from one of the nine sites of emission. With such a short lifetime for methane (1 year), atmospheric transport can produce pulses of methane at Gale crater that are superimposed onto the slow seasonal variation due to the $\mathrm{CO}_{2}$ condensation/sublimation cycle. The largest pulses simulated by the GCM $(\sim 1.6$ ppbv) are obtained when the source is located at Apollinaris Patera, east of Gale Crater. However, they are 4 times smaller than those measured by TLS, and do not occur during the season observed by the instrument. A methane source located at Martz Crater (south of Gale Crater) provides a better result for seasonality, but requires a much larger release to match the pulse of 7 ppbv observed by TLS.
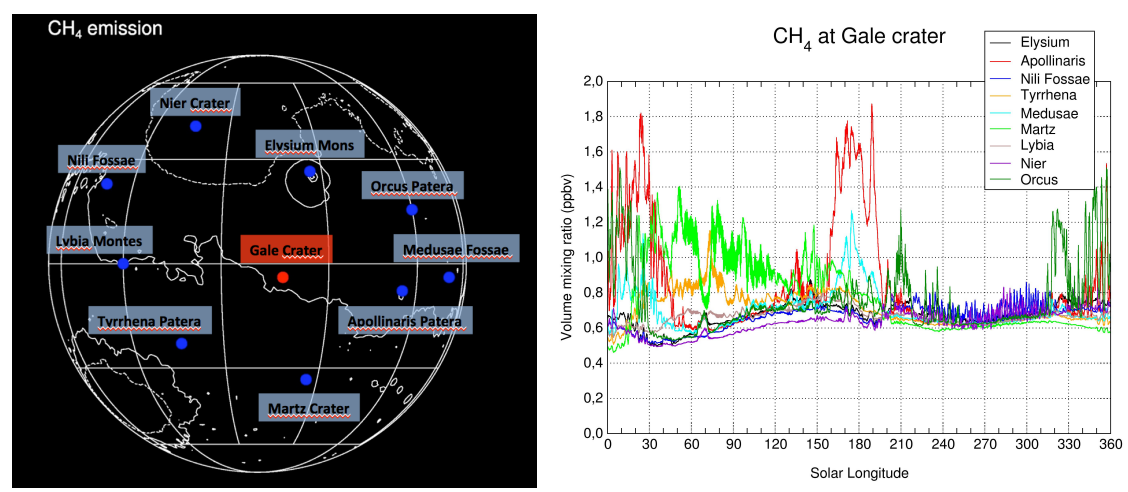

Figure 12.6. Simulations of methane with the LMD global climatechemical model. Left: Location of each site of emission of methane tested for the nine model experiments. In each case the emission is continuous and the methane lifetime is arbitrarily assumed to be 1 terrestrial year. Right: Seasonal evolution of the mixing ratio of methane obtained at Gale Crater for each of the sites of emission. 
As shown in Figure 12.7, a pulse peaking at 7 ppbv in the model simulation requires a methane lifetime of the order of 1 month in order to maintain the same background level of $0.7 \mathrm{ppbv}$. Such a short lifetime puts an enormous burden on the process that governs the destruction of methane on Mars, which must be faster than the conventional chemistry by three orders of magnitude. The fact that such a strong, unknown, chemical process would have been overlooked would be a surprise since conventional models do a rather good job at reproducing short-lived chemical species on Mars. For instance, species that are very sensitive to the oxidizing capacity of the atmosphere, such as hydrogen peroxide $\left(\mathrm{H}_{2} \mathrm{O}_{2}\right)$ or ozone $\left(\mathrm{O}_{3}\right)$, are measured in quantities that are quite consistent with model simulations including only the standard set of chemical reactions used in Earth photochemistry (e.g., Encrenaz et al 2015; Clancy et al 2016).

Several studies have explored the possibility of a fast-acting sink of methane in the specific atmospheric conditions of Mars. For instance, it has been proposed that methane could be destroyed by electrochemical reactions triggered by the strong electric fields generated by local 'dust devils' or during regional-scale dust storms (Delory et al 2006; Farrell et al 2006). During such events, energized electrons are expected to dissociate methane directly but also to dissociate $\mathrm{H}_{2} \mathrm{O}$ and produce vast amounts of $\mathrm{H}_{2} \mathrm{O}_{2}$. This latter effect is problematic, however, since the large-scale production of $\mathrm{H}_{2} \mathrm{O}_{2}$ by electric fields is contrary to the good agreement currently noted between observations and conventional models of $\mathrm{H}_{2} \mathrm{O}_{2}$ and $\mathrm{O}_{3}$. Lefèvre and Forget (2009) used a GCM to demonstrate that electrochemistry should, in addition to $\mathrm{H}_{2} \mathrm{O}_{2}$, also produce large amounts of $\mathrm{CO}$ from the dissociation of $\mathrm{CO}_{2}$. Nonetheless, both of these facts are difficult to reconcile with current observations of $\mathrm{H}_{2} \mathrm{O}_{2}$ and $\mathrm{CO}$, which show no significant enhancement during the dusty season. Fast destruction of methane at the global scale by electrochemical processes is therefore not supported for the moment by observations.

Atreya et al $(2006,2007)$ argued that the local excesses of $\mathrm{H}_{2} \mathrm{O}_{2}$ produced in dust storms could lead to its precipitation out of the atmosphere onto the Martian surface. Methane would then be scavenged by large amounts of $\mathrm{H}_{2} \mathrm{O}_{2}$ or other super-oxides embedded in the regolith. This process has the advantage of not altering the conventional atmospheric chemistry, but it is difficult to imagine that it could affect $\mathrm{CH}_{4}$ without processing $\mathrm{O}_{3}$ or $\mathrm{CO}$ in the same fashion. Furthermore, rapid loss of methane in the regolith is, at present, not supported by laboratory work: experiments on analogues of Martian soil or perchlorates show no fast oxidation of methane in the presence of $\mathrm{H}_{2} \mathrm{O}_{2}$ (Gough et al 2011). In addition, kinetic data on the reactions 
between $\mathrm{CH}_{4}$ with metal oxides and superoxide ions are extremely slow at Martian temperatures (Krasnopolsky 2006).

Another potential explanation for the apparent variability and short lifetime of methane on Mars was presented by Knak Jensen et al (2014), who found that wind-driven agitation of quartz crystals could produce active sites that sequester methane temporarily. Crystalline quartz is very rare on Mars but is used in their experiments as an analogue for the silicate mineralso found in airborne dust or at the surface. The reverse reaction that releases $\mathrm{CH}_{4}$ back to the atmosphere has not been studied in the laboratory and, thus, the efficiency of these idealized experiments in the real Martian atmosphere is highly uncertain. Another possibility is that methane condenses in clathrates, however, according to laboratory work (Trainer et al 2010), the trapping of $\mathrm{CH}_{4}$ on polar ice analogues, including clathrates, appears to be negligible under modern Martian conditions and is not a viable explanation for the apparent variability of methane on Mars.

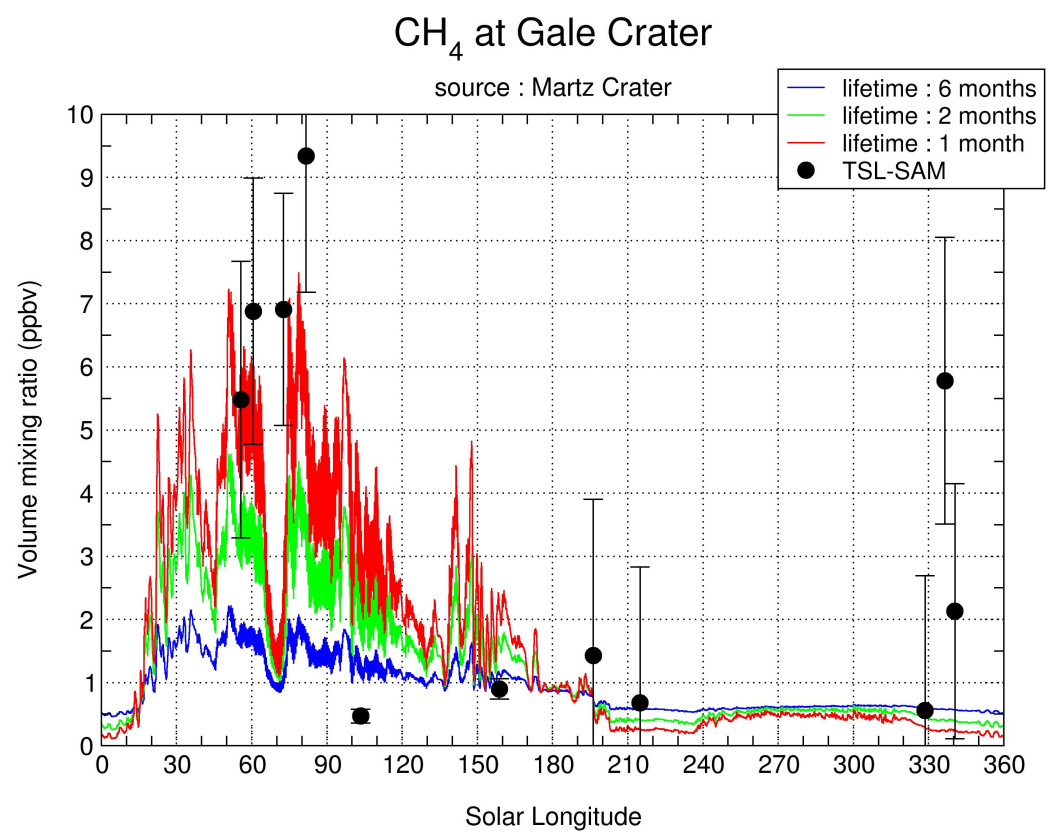

Figure 12.7. Seasonal evolution of the mixing ratio of methane (ppbv) at Gale Crater calculated by the LMD global climate model when methane is continuously released from Martz Crater. The results are shown for arbitrary lifetimes of methane of 1,2 , and 6 months and are compared to TLS measurements by Webster et al (2015a). 


\subsection{Open questions and future measurements}

The detection of a very low background level ( $\sim 0.5 \mathrm{ppbv})$ of methane in the atmosphere of Mars by the Curiosity rover raises the possibility of a planet that is biologically or geologically active now. However this detection does not constitute proof of such activity: we have seen that the production of methane required to explain the TLS observations is so minor that these results could equally be due to the slow UV-alteration of the organics delivered by inert meteoric or interplanetary dust material. In fact, for the atmospheric chemist, the variations of Martian methane pose a much greater challenge than just its presence. For robust theoretical reasons, based on knowledge well-established in the context of the atmosphere of the Earth, methane should have a 300-year lifetime on Mars. Due to this long lifetime with respect to mixing by transport, methane should therefore be uniformly distributed throughout the atmosphere. Similarly to other long-lived species observed on Mars (such as argon, or carbon monoxide), methane variations should only be controlled by the slow condensation/sublimation cycle of $\mathrm{CO}_{2}$ with peak-to-peak amplitudes of about $30 \%$ over one Martian year. Yet, the observations of Martian methane by TLS suggest variations of up to one order of magnitude in less than two months. This implies not only a local methane source situated by extraordinary coincidence very close to the Curiosity rover, but also that an unknown and extraordinarily fast mechanism of methane destruction is at work. Because this finding strongly challenges our current understanding of the atmospheric chemistry and physics of Mars, the discovery of variable amounts of methane needs to be confirmed by further detections. In particular, the question "is methane variable on Mars?" must now be addressed by mapping methane at the global scale, with a sensitivity better than $1 \mathrm{ppbv}$. Evidently the answer to this question is a prerequisite before tackling the following ones, such as "where are the emission sites of methane?", "how is methane destroyed?", and ultimately "how is methane produced?". Confirming the presence and variability of methane on Mars is one of the objectives of ESA-Roscomos Trace Gas Orbiter (TGO), which launched in March 2016 and arrived at Mars in October 2016. After a long aerobraking phase, the nominal science operations of TGO will have started in 2018. On board the platform, two different instruments, the Atmospheric Chemistry Suite (ACS) (Korablev et al 2018) and NOMAD (Vandaele et al 2015), will use the solar occultation technique to search for methane at all locations and seasons with a sensitivity hopefully better than $0.1 \mathrm{ppbv}$. It is therefore likely that a major advance is coming in our effort to unravel an enigma that may impact Mars science and astrobiology in a fundamental way. 


\section{References}

Atreya SK, Wong AS, Renno NO et al (2006) Oxidant Enhancement in Martian dust devils and storms: implications for life and habitability. Astrobiology 6:439-450

Atreya SK, Mahaffy PR, Wong AS (2007) Methane and related trace species on Mars: Origin, loss, implications for life and habitability. Planet Space Sci 55:358-69

Ciais P, Sabine C, Bala G et al (2013) Carbon and Other Biogeochemical Cycles. In Stocker TF, Qin D, Plattner G.K. et al (eds): Climate Change 2013: The Physical Science Basis. Contribution of Working Group I to the Fifth Assessment Report of the Intergovernmental Panel on Climate Change. Cambridge University Press, Cambridge, United Kingdom and New York, NY, USA:465-570

Clancy RT, Sandor BJ, Wolff MJ et al (2000) An intercomparison of ground-based millimeter, MGS TES, and Viking atmospheric temperature measurements: Seasonal and interannual variability of temperatures and dust loading in the global Mars atmosphere. J Geophys Res 105:9553-9572 Clancy RT, Wolff MJ, Lefèvre F et al (2016) Daily global mapping of Mars ozone column abundances with MARCI UV band imaging. Icarus 266:112-133

Court RW, Sephton MA (2009) Investigating the contribution of methane produced by ablating micrometeorites to the atmosphere of Mars. Earth Planet Sci Lett 288: 382-385

Delory GT, Farrell WM, Atreya SK et al (2006) Oxidant Enhancement in Martian dust devils and storms: electric fields and electron dissociative attachment. Astrobiology 6:451-462

Encrenaz T, Fouchet T, Melchiorri R et al (2006) Seasonal variations of the martian CO over Hellas as observed by OMEGA/Mars Express. Astron Astrophys 459:265-270

Encrenaz T, Greathouse TK, Lefèvre F et al (2015) Seasonal variations of hydrogen peroxide and water vapor on Mars: Further indications of heterogeneous chemistry. Astron Astrophys 578:A127

Etiope G, Sherwood Lollar B (2013) Abiotic methane on Earth. Rev. Geophys 51:276-299

Farrell WM, Delory GT, Atreya SK (2006) Martian dust storms as a possible sink of atmospheric methane. Geophys Res Lett doi:10.1029/2006GL027210

Fonti S, Marzo, GA (2010) Mapping the methane on Mars. Astron. Astrophys 512:A51

Formisano V, Atreya, SK, Encrenaz T et al (2004) Detection of methane in the atmosphere of Mars. Science 306:1758-1761 
Geminale A, Formisano V, Sindoni G (2011) Mapping methane in martian atmosphere with PFS-MEX data. Planet Space Sci 59:137-148

Gough RV, Turley JJ, Ferrell GR et al. (2011) Can rapid loss and high variability of martian methane be explained by surface $\mathrm{H}_{2} \mathrm{O}_{2}$ ? Planet Space Sci 59:238-246

Kelley DS, Karson JA, Fruh-Green GL et al (2005) A serpentinite-hosted ecosystem: The lost city hydrothermal field. Science 307:1428-1434

Keppler F, Vigano I, McLeod, A et al (2012) Ultraviolet-radiation-induced methane emissions from meteorites and the Martian atmosphere. Nature 486:93-96

Knak Jensen SJ, Skibsted J, Jakobsen HJ et al (2014) A sink for methane on Mars ? The answer is blowing in the wind. Icarus 236:24-27

Korablev O, Montmessin F, Trokhimovskiy A, et al (2018) The Atmospheric Chemistry Suite (ACS) of three spectrometers for the ExoMars 2016 Trace Gas Orbiter. Space Sci Rev 214:7

Krasnopolsky VA, Maillard JP, Owen TC (2004) Detection of methane in the martian atmosphere: evidence for life? Icarus 172:537-547

Krasnopolsky VA (2006) Some problems related to the origin of methane on Mars. Icarus 180:359-367

Krasnopolsky VA (2012) Search for methane and upper limits to ethane and $\mathrm{SO}_{2}$ on Mars. Icarus 217:144-152

Lefèvre F, Forget F (2009) Observed variations of methane on Mars unexplained by known atmospheric chemistry and physics. Nature 460:720-723 Mumma MJ, Villanueva GL, Novak RE et al (2009) Strong release of methane on Mars in northern summer 2003. Science 323:1041-1045

Oze C, Sharma M (2005) Have olivine, will gas: Serpentinization and the abiogenic production of methane on Mars. Geophys. Res. Lett. 32:L10203

Roos-Serote M, Atreya SK, Webster CR et al (2016) Cometary origin of atmospheric methane variations on Mars unlikely. J Geophys Res 121:2108-2119

Sprague AL, Boynton WV, Kerry KE et al (2007) Mars' atmospheric argon: Tracer for understanding Martian atmospheric circulation and dynamics. J Geophys Res 112: E03S02

Summers ME, Lieb, BJ, Chapman E et al (2002) Atmospheric biomarkers of subsurface life on Mars. Geophys Res Lett 29:24

Trainer MG, Tolbert MA, McKay CP et al (2010) Limits on the trapping of atmospheric $\mathrm{CH}_{4}$ in martian polar ice analogs. Icarus 208:192-197

Vandaele A, Neefs E, Drummond R et al (2015) Science objectives and performances of NOMAD, a spectrometer suite for the ExoMars TGO mission. Planet Space Sci 119:233-249 
Villanueva GL, Mumma MJ, Novak RE et al (2013) A sensitive search for organics $\left(\mathrm{CH}_{4}, \mathrm{CH}_{3} \mathrm{OH}, \mathrm{H}_{2} \mathrm{CO}, \mathrm{C}_{2} \mathrm{H}_{6}, \mathrm{C}_{2} \mathrm{H}_{2}, \mathrm{C}_{2} \mathrm{H}_{4}\right)$, hydroperoxyl $\left(\mathrm{HO}_{2}\right)$, nitrogen compounds $\left(\mathrm{N}_{2} \mathrm{O}, \mathrm{NH}_{3}, \mathrm{HCN}\right)$ and chlorine species $\left(\mathrm{HCl}, \mathrm{CH}_{3} \mathrm{Cl}\right)$ on Mars using ground-based high-resolution infrared spectroscopy. Icarus 223:11-27

Webster CR, Mahaffy PR, Atreya SK et al (2013) Low upper limit to methane abundance on Mars. Science 342:355-357

Webster, CR, Mahaffy, PR, Atreya SK et al (2015a) Mars methane detection and variability at Gale crater. Science 347:415-427

Webster, CR, Mahaffy PR, Atreya SK et al (2015b) Mars methane detection and variability at Gale Crater measured by the TLS instrument in SAM on the Curiosity rover. Abstract P438-2110, Fall Meeting AGU

Zahnle K, Freedman, RS, Catling DC (2011) Is there methane on Mars? Icarus 212:493-503 


\section{Sources}

Figure 12.1: after Mumma et al (2009) / permission

Figure 12.2: after Webster et al (2015a) / permission

Figure 12.3: adapted from Webster et al (2015a) and Roos-Serote et al (2016)

Figure 12.4: after Lefèvre and Forget (2009) / permission

Figure 12.5: original figure made for the chapter. TLS data from Webster et al (2015a) and Roos-Serote et al (2016)

Figure 12.6: original figure made for the chapter.

Figure 12.7: original figure made for the chapter. TLS data from Webster et al (2015a) 